\title{
Coral reef fishes use crown-of-thorns seastar as habitat
}

Received: 25 August 2008/Accepted: 28 October 2008/Published online: 18 November 2008

(C) Springer-Verlag 2008

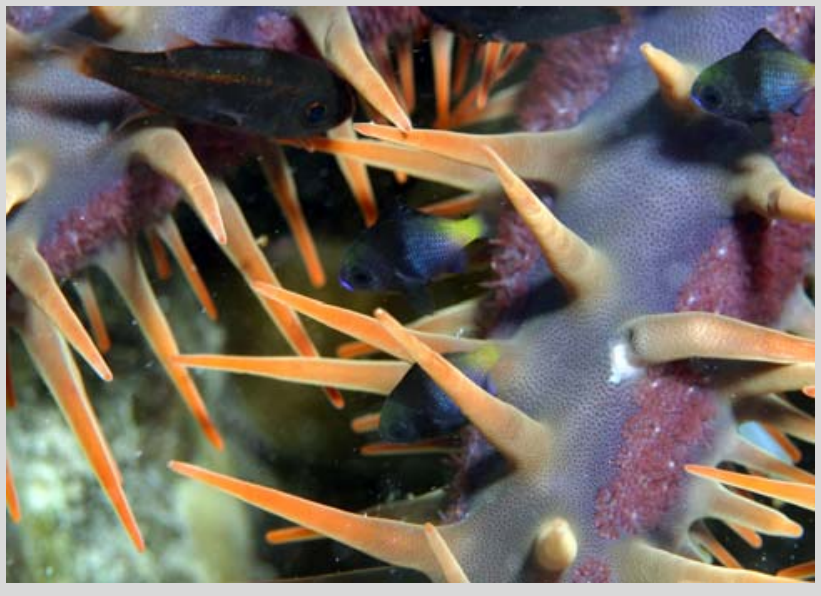

Fig. 1 Dascyllus flavicaudus and Siphamia sp. (upper left) sheltering amongst the spines of Acanthaster planci. Photo by M.A. Steele
Between January and July 2008, we observed an unusual association between several species of coral reef fishes and the corallivorous crown-of-thorns seastar Acanthaster planci within the lagoon of Moorea, French Polynesia $\left(17^{\circ} 30^{\prime} \mathrm{S}\right.$ : $\left.149^{\circ} 50^{\prime} \mathrm{W}\right)$. Four species of recently settled damselfishes (Pomacentrus pavo, Dascyllus aruanus, D. flavicaudus, and D. trimaculatus) as well as juveniles and adults of a cardinalfish (Siphamia sp.) were seen sheltering within the venomous spines of Acanthaster. Three of the damselfish species normally occupy branching corals throughout their lives, one occupies sea anemones when young and shifts to general coral reef habitat when older, and the cardinalfish, an undescribed species (O. Gon and J. Randall, pers. comm.), appears to normally associate with sea urchins.

Fishes only inhabited Acanthaster when the seastars occurred on sandy substrate at least several meters away from corals. Surveys done in January along four $200 \times 10 \mathrm{~m}$ transects $(5,10,15$, and $20 \mathrm{~m}$ depth) revealed that 6 out of 29 Acanthaster were occupied by cardinalfish (2-18 fish per seastar, mean $=6.2$ ). All occupied seastars were more than $5 \mathrm{~m}$ from the reef, whereas none of the Acanthaster less than $5 \mathrm{~m}$ from the reef contained fishes. The four damselfish species noted above were not seen during this survey, but we observed them occupying Acanthaster at other times during January (Fig. 1), also only when the host seastar was distant from the reef. During surveys in June along three transects $(5,10$, and $20 \mathrm{~m}$ depth), we observed 11 Acanthaster and three of these that were more than $5 \mathrm{~m}$ from the reef were occupied by cardinalfish $(2-9$ per seastar, mean $=4.3)$ and one also had a single damselfish that was too small and unpigmented to identify.

We know no prior records of damselfishes occupying Acanthaster. The outcome of this apparently short-term, opportunistic, commensal relationship is unclear. Only recently settled damselfishes were seen inhabiting Acanthaster, implying that individuals either move to more typical habitat after settling on Acanthaster, perhaps when seastars move near the reef, or die. In contrast, all life stages of the cardinalfish Siphamia sp., from recent settlers to adults mouthbrooding eggs were found on Acanthaster, as has been noted for other members of this genus (e.g., Allen 1972). These observations reveal previously unappreciated flexibility in the range of habitats used by several coral reef fishes. Future studies will be necessary to document whether this association persists beyond the current outbreak of Acanthaster and to determine the types and magnitude of potential effects on the population dynamics of the fish species involved.

Acknowledgments We thank C. Lantz for assistance in the field, and three anonymous reviewers for helpful comments. Funding was provided by Northeastern University's Three Seas Marine Biology program as well as the National Science Foundation (OCE 04-17412).

\section{Reference}

Allen GR (1972) Observations on a commensal relationship between Siphamia fuscolineata (Apogonidae) and the crown-of-thorns starfish, Acanthaster planci. Copeia 3:595

A. C. Stier $(\bowtie)$

Department of Zoology, University of Florida, Gainesville, FL 32611-8525, USA

e-mail: astier@zoology.ufl.edu

M. A. Steele

Department of Biology, California State University, 18111 Nordhoff Street, Northridge, CA 91330-8303, USA

A. J. Brooks

Coastal Research Center, Marine Science Institute, University of California Santa Barbara, Santa Barbara, CA 93106-6150, USA

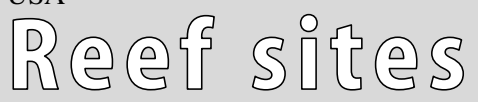

Coral Reefs (2009) 28:227

DOI $10.1007 / \mathrm{s} 00338-008-0445-9$ 